perifèria

Número 20 (2), diciembre 2015

revistes.uab.cat/periferia

\title{
La memòria recuperada: I'ús dels relats biogràfics en la segona i tercera generació dels emigrants valencians als Estats Units d'Amèrica a principi del segle $x x$
}

\author{
Pepa García-Hernandorena- Universitat de València ${ }^{1}$
}

DOI: http://dx.doi.org/10.5565/rev/periferia.461

\section{Resum}

És habitual, quan es fa ús del mètode biogràfic, recollir els relats directament d'aquells que van viure els fets narrats, siguin aqueststota una vida o alguns aspectes que l'investigador desitja que siguin destacats. En la investigació duta a terme sobre la recuperació de la memòria dels emigrants valencians als Estats Units d'Amèrica durant les dues primeres dècades del segle XX això es presenta com un fet impossible: els que van viure en primera persona l'emigració ja han desaparegut. Es podria pensar que amb ells desapareixien també les seues històries. Però gràcies a un exhaustiu treball amb els seus descendents (filles i fills, nétes i néts, nebodes i nebots) i fent ús de tècniques que són pròpies d'aquesta metodologia com entrevistes obertes de caire biogràfic, anàlisi de correspondència $i$ altres documents com ara fotografies, va sent possible recuperar un patrimoni que d'una altra manera hagués acabat esvaint-se.

El treball que ací es presenta gira així entorn de diverses qüestions: si les vides són narrades per uns altres: què és el que recorden? com ho recorden? com ho transmeten?.

Paraules clau:mètode biogràfic, valencians als EEUU, memòria recuperada, descendents emigrants

\begin{abstract}
When making use of the biographic method, it's quite common to collect stories directly from those who lived the narrated events. Those stories can be focused either in their whole live, either in some aspects that the researcher considers relevant or important. There's an impossible fact related to the research carried out on the recovery of the memory of Valencia immigrants to the United States of America during the first two decades of the 20th Century: those who emigrated
\end{abstract}

\footnotetext{
${ }^{1}$ Enviar correspondència a: Pepa García Hernandorena magarhe4@alumni.uv.es
} 


\section{perifèria}

Número 20 (2), diciembre 2015

revistes.uab.cat/periferia

have already passed away. You may think that their stories also disappear with them.

However, thanks to an exhaustive work with their descendants (sons, daughters, grandsons and granddaughters, nephews and nieces) and making use of techniques that are closely related to this methodology (biographical-oriented interviews, analysis of correspondence and other documents such as photographs), it is still possible to recover assets that otherwise would have ended up disappearing.

The work presented here is organized around some issues. If others narrate those lives: What do they remember? How do they remember it? How do they transmit it?

Keywords: biographical method, Valencia immigrants in USA, recovered memory, emigrant's descendants.

\section{Introducció}

L'emigració de valencians als Estats Units d'Amèrica a principis del segle XX i les seues conseqüències socials, econòmiques, culturals i de qualsevol altre tipus, tant a nivell individual com col-lectiu ens són pràcticament desconegudes ${ }^{2}$. No han sigut mai objecte de cap investigació, recerca o treball des de l'acadèmia ${ }^{3}$. Exceptuant algunes publicacions locals o comarcals a llibres de festes 0 similars $^{4}$ no $\mathrm{s}^{\prime}$ ha realitzat mai un treball rigorós que situeaquest fenomen entre altres més coneguts $i$ que varen compartir contextos temporals i espacials: alacantins a Algèria, per exemple ${ }^{5}$. La publicació I'any 2012 del text de Teresa Morell, Valencians a Nova York. El cas de la Marina Alta (1912-1920) és l'intent més rigorós d'explicar i mostrar què va succeir fa quasi cent anys a una part del territori valencià, des d'una perspectiva quantitativa i descriptiva. L'altre intent de donar-li forma i contingut a aquest fenomen ha estat un treball emmarcat en el periodisme d'investigació, la sèrie de documentals Del Montgó a Manhattan, de la productora Info TV estrenat I'any 2014 i dirigit pel periodista Juli Esteve.

\footnotetext{
${ }^{2}$ Així mateix són també poc nombrosos les investigacions al voltant de l'emigració espanyola cap a aquest país d'Amèrica del Nord. Trobem el treball pioner i quasi únic de Rueda (1993) i més pròxim en el temps, una tesi doctoral de la Universitat de Califòrnia a càrrec de Varela-Lago (2008).

${ }^{3} \mathrm{~A}$ les Actes de les Jornades sobre I'emigració dels valencians a Amèrica celebrades amb motiu del $\mathrm{V}$ Centenari del Descobriment I'any 1993 es troba una ponència, recollida en dos fulls, a càrrec de Joan Francesc Mira, que tracta el tema per damunt.

${ }^{4}$ Per citar-ne alguns: Garcia-Hernandorena (2013); Ortuño (2013); Morrió (2014).

${ }^{5}$ Menages i Monjo (2007), Bonmatí, (1988).
} 


\section{perifèria}

Número 20 (2), diciembre 2015

revistes.uab.cat/periferia

De veres és que els emigrants procedents de terres valencianes cap als Estats Units $\mathrm{d}^{\prime}$ Amèrica foren molt menys nombrosos que els que eixien cap altres destinacions ${ }^{6}$, però per alguns pobles de les comarques de la Marina Alta, La Marina Baixa o el Comtat va significar un èxode de persones que va tenir importants conseqüències a tots el nivells. Per exemple a Benilloba, localitat situada a l'interior muntanyenc de la província d'Alacant. Segons el padró municipal de l'any 1913 el poble tenia 1.086 habitants, dels quals 620 eren homes. Entre els anys 1916 i 1920, eixiren 150 persones amb destinació els Estats Units d'Amèrica. La pràctica totalitat eren homes (un 99\%) i el 76\% tenien 30 anys o menys (Morrió 2014). Pocs van ser els que es van quedar de manera definitiva a aquell país ja que la majoria retornaren al cap d'un temps.Així apareix una de les principals característiques que va tenir aquesta emigració: en línies generals va ser una emigració masculina, de tipus "oroneta"7: homes joves en un viatge d'anada i tornada buscant uns salaris molt més elevats que els que ací es podien trobar, amb la intenció de retornar en les butxaques plenes per poder casar-se, comprar-se una casa, un bancal o establir un negoci. Encara que també es pot seguir el rastre d'algunes dones, les quals, amb companyia dels seus marits o germans, formaren part d'aquest moviment migratori.I, com ja s'ha assenyalat, encara que no va ser el més habitual, en alguns casos per a l'emigrant el viatge va ser definitiu i acabaren establint-se amb les seues famílies al país nord-americà.

Els protagonistes del fets als que ens referirem ja fa anys que desaparegueren, però no així les seues vivències i hem buscat els seus descendents directes per rescatar-les, traure-les a la llum, donar-les a conèixer. El nostre objectiu és, a partir de la recopilació dels relats d'uns fets ja passats, elaborats pels descendents directes d'aquells emigrants recuperar, en primer Iloc, una part important de la

\footnotetext{
${ }^{6}$ Algunes xifres per contextualitzar quantitativament aquest fenomen: entre 1906 i 1920 emigraren cap a l'Argentina al voltant d'un milió d'espanyols; cap a Algèria es dirigiren al voltant de 300.000 i als Estats Units d'Amèrica ho feren uns 140.000 (Sánchez 1995). El valencians que triaren els EEUU han sigut comptabilitzats al treball ja esmentat d'Info TV (2014): 15.600 dels espanyols que entraren als EEUU pel port de Nova York entre 1906 i 1920 eren valencians.

${ }^{7}$ Per altra banda, eixa era el tipus d'emigració tradicional que es feia des de les comarques alacantines cap a terres manxegues o castellanes, també cap a altres comarques valencianes com la Ribera del Xúquer, seguint el cicle dels conreus i de les collites (cereal, vinya, arròs). També l'emigració cap a Algèria es feia generalment de manera temporal (Bonmatí 1988).
} 


\section{perifèria}

Número 20 (2), diciembre 2015

revistes.uab.cat/periferia

història del nostre territori i les seues gents. En segon Iloc veure com aquestes experiències migratòries ha configurat d'alguna manera la identitat individual i col-lectiva dels nostres pobles, les nostres gents. Donades les característiques del nostre objecte d'estudi l'aproximació que realitzem la fem des de la subjectivitat i amb la voluntat de rescatar "las historiasparticulares (de género, de clase, de país, de linaje) [que] tratan de abrirsepaso a través de los discursos canónicos de la historia" (Marinas i Santamarina 1993: 11), i a l'igual que assenyalen aquestos autors, atenent el nostre interès "por los procesos de la memoria individual, grupal i colectiva" (ibíd: 11). Mitjançant l'enfocament biogràfic ens fem ressò de la complexitat del comportament humà, de les seues motivacions i de la seua subjectivitat, a més a més tenim davant un objecte diacrònic, que ha evolucionat amb el temps i aquest I'ha transformat. Des d'aquesta perspectiva incorporem el punt de vista de l'objecte a la investigació i a més a més accedim a una informació que no es pot obtenir d'altra manera.

A un nivell general,Carles Feixa fa unarevisió de I'aplicació del mètode biogràfic i dels materials utilitzat per aquest al llarg d'una sèrie d'obres produïdes per les Ciències Socialsdurant el segle XX i que "han utilizado las narrativaspersonales en la generación de discursos académicos sobre el cambio social" (2006:4). Per altra banda, l'aplicació d'aquest procediment quan es parla de la recerca sobre migracions el podríem considerar ja clàssic des de la publicació de Thomas i Znaniecki, ThePolishPeasant in Europe andAmerica ${ }^{8}$, publicat als anys vint del segle passat. És dels més usats quan del que es tracta es de reconstruir trajectòries de migrants. Joan Prat ens ofereix una visió panoràmica i de conjunt al voltant dels relats $\mathrm{i}$ històries de vida en relació al processos migratoris que han donat lloc a obres fonamentals dins de les Ciències Socials i que han utilitzat "relatosautobiogràficosindividuales 0 múltiples y dentro de éstos los Ilamadosparalelos y/o cruzados (Pujadas 1992: 41 y ss)" (2007b:22). Les deu primeres pàgines del seu article "En busca del paraiso: historias de vida y migración" estan dedicades a aquells que emigraren a Amèrica als anys inicials del

\footnotetext{
${ }^{8}$ Disposem d'una traducció al castellà editada per Juan Zarco, amb pròleg de Ken Plummer i editada pel CIS el 2004. És una selecció de l'obra original i no inclou la història de vida de Wladeck.
} 


\section{perifèria}

Número 20 (2), diciembre 2015

revistes.uab.cat/periferia

segle XX. La majoria són d'emigrants que es dirigiren cap als països d'Amèrica Central (Cuba) o del Sud (Argentina) encara que també s'anomena el cas dels bascs als Estats Units ${ }^{9}$ (2007b). En el nostre treball seguim a aquest autor pel que fa a la definició d'emigrants: " el emigrante es el que realiza la partida o el éxododesde el punto de vista de sulugar de procedència", i també del fet o l'acció de migrar com "cambio espacial que implica, como mínimo, una nueva residencia y a menudo una nuevasociedad, unascostumbresdistintas, etc" (Prat 2007a:221). I encara que nosaltres no hem entrevistat directament a aquestos emigrants sinó els seus descendents ${ }^{10}$, $\mathrm{i}$ el nostre objectiu no són tant els processos migratorisper se sinó les conseqüències directes en les trajectòries vitals de moltes famílies, comunitats i pobles que va comportar el fet de migrar.

\section{Metodologia}

L'ús d'una metodologia qualitativa, el mètode biogràfic, es mostra com una potent eina per a rescatar de l'oblit aquestsesdeveniments ocults pel pas del temps, desconeguts i oblidats en moltes de les comarques i localitats on van ocórrer i per tal d'accedir a una informació guardada en els calaixos de moltes còmodes i de moltes memòries. Dins de l'enfocament biogràfic hem utilitzat la tècnica dels relats biogràfics múltiples i paral-lels (Pujadas [1992] 2000). Aquesta tècnica s'utilitza quan la unitat d'anàlisi és prou ampla però hi ha un tret que conforma una certa identitat col-lectiva. En la nostra investigació seria el fenomen de l'emigració cap als Estats Units d'Amèrica a principis del segle XX el que ens dóna les característiques de l'univers a estudiar.

La primera tasca en el nostre disseny de la investigació va ser la definició d'uns criteris els quals ens servirien per a la selecció d'informants. Els criteris van ser quatre: territorial, temporal, parentiu i gènere. Pel que fa al punt de vista del

\footnotetext{
${ }^{9}$ Pot ser aquest siga el cas més conegut i més tractat quan ens referim a l'emigració als Estats Units des de l'estat espanyol. El cas dels pastors bascs emigrats a l'oest d'aquest país nord-americà ha donat fins i tot per a l'existència d'un Centre for BasqueStudies a la Universitat de Nevada, Reno, que conserva i custodia el llegat d'aquells.

${ }^{10}$ I la condició d'emigrant evidentment no s'hereta (Moncusí 2007).
} 


\section{perifèria}

Número 20 (2), diciembre 2015

revistes.uab.cat/periferia

territori seleccionarem els informants que anaven a formar part de la nostra investigació en base a dos indrets espacials: en primer lloc a les comarques valencianes des d'on eixiren aquells emigrants $i$ on hem buscat els seus descendents; en segon Iloc els estats dels EEUU on aquells s'establiren i on encara es pot seguir el rastre de la presència valenciana.A aquest article es presenten els resultats de la investigació duta a terme en quatre comarques valencianes: dues de la província d'Alacant i dues de la de València. La província d'Alacant va ser d'on eixiren el primers emigrants cap a Nord-Amèrica (Canadà i els EEUU) el $1906^{11}$, també va ser el lloc d'on n'eixiren més i, probablement, on aquest fet ha estat més present entre els seus habitants i és més conegut. Dins de la província vam escollir dues comarques: la Marina Alta, on realitzàrem els primers contactes i entrevistàrem el primer informant; i el Comtat, comarca que també va veure com molts dels seus pobles es quedaven sense homes en anar-se'n tots a Amèrica (com el cas anteriorment citat de Benilloba). A la província de València escollírem la comarca de la Safor, limítrof pel sud amb la Marina Alta i pel nord amb la Ribera Alta, I'altra comarca d'esta província que s'ha inclòs a la investigació. A I'última comarca I'emigració cap als Estats Units d'Amèrica es va produir de manera més tardana i amb menys intensitat. Va estar molt localitzada espacial i temporalment: va afectar bàsicament tres localitats (Alginet, Carlet i Guadassuar) i tots els emigrants eixiren l'any $1920^{12}$. Pel que fa als que es quedaren als EEUU, realitzàrem entrevistes als descendents d'aquells valencians que s'establiren als estats de Connecticut i Nova York.

\footnotetext{
${ }^{11}$ L'elecció d'aquesta data no és casual ni arbitrària. L'any 1906 eixí cap al Canadà la primera expedició de treballadors alacantins, des del poble d'Orba. Des d'allí passaren als EEUU i eixe pareix ser l'inici de la corrent migratòria cap a aquest país (Morell 2012).

${ }^{12}$ L'any 1921 el Congrés dels Estats Units aprovà una Ilei, I'anomenada "Llei de quotes d'emergència" que restringí l'entrada d'immigrants al país (un $3 \%$ sobre la població de cada nacionalitat segons el cens de 1910). Esta restricció afectà sobretot a aquells procedents dels països del sud i l'est d'Europa. Açò explicaria que I'any 1920 es produirà la major afluència d'immigrants per por a l'aplicació d'esta llei. L'any 1924 una altra llei, "Llei dels Orígens Nacionals", rebaixa el percentatge d'immigrants a un 2\% i pren com a base per els càlculs de les quotes el cens de 1890. Açò deixava fora pràcticament els valencians ja que segons eixa llei només podien entrar-hi 131 emigrants espanyols per any (al cens de 1890 no hi havia pràcticament espanyols).
} 


\section{perifèria}

Número 20 (2), diciembre 2015

revistes.uab.cat/periferia

Continuant amb el segon criteri, el temporal, buscàrem i escollírem informants els avant-passats dels quals havien emigrat als Estats Units d'Amèrica entre els anys 1906 i 1920. En tercer Iloc i per parentiu, en primer lloc entrevistàrem fills o filles dels emigrants; fet que determinà en certa mesura el gènere dels nostres informants. Ens trobarem amb una majoria de dones, ja que donada l'elevada edat d'aquests descendents resulta més fàcil trobar dones que homes (I'esperança de vida entre les dones és més alta). També les entrevistes que hem realitzat a dones solen ser més extenses que les dels homes. El gènere per tant, és un aspecte a tenir en compte quan es parla de conservació i recuperació de memòria (Comas d'Argemir et al. 1990). Entrevistàrem nebots i nebodes en considerar que la relació amb el tio d'Amèrica havia sigut constant i fluïda i la seua història estava ajustada amb una història familiar conjunta més enllà de la simple família nuclear.

Les entrevistes tingueren un caràcter semiestructurat i les narracions van anar sorgint al voltant d'uns materials visuals i personals (fotografies, postals, passaports, revistes de l'època) i d'uns objectes (baguls, maletes, monedes, càmeres fotogràfiques) portats pels emigrants, aportats pels informants $i$ ben conservats per ells. Els materials i objectes es converteixen així en una eina de primer nivell per percebre $\mathrm{i}$ entendre les pràctiques de la memòria (DornierAgbodjan2004). Segons aquesta autora, les fotografies de família (i en el nostre cas, també els objectes) contindrien els tres marcs socials de la memòria tal i com van ser definits Maurice Halbwasch (el llenguatge, el temps i l'espai; però també la família, el gènere o la classe social, afegiríem nosaltres), és estable i col-lectiva i la seua funció principal al si de la família és ser un recordatori, una provocació de la memòria. Per tant, les fotografies i altres documents zelosament guardats per les famílies han sigut escanejats i afegits als relats formant part de la investigació.

\section{Etnografia i resultats}

A la taula 1es pot veure el perfil dels informants segons els criteris que hem anat citant.

En la primera fase del nostre treball de camp realitzada entre 2012 i 2014,s'han arreplegat19 relats. Segons la distribució territorial, un $47 \%$ els hem recollita la província d'Alacant ( $33 \%$ a la Marina Alta; $67 \%$ al Comtat) i un $53 \%$ a la de 


\section{perifèria}

Número 20 (2), diciembre 2015

revistes.uab.cat/periferia

València (20\% a la Safor; $80 \%$ a la Ribera Alta). El $84 \%$ són descendents d'emigrants que retornaren; la resta ho són d'aquells que no ho feren. El mateix percentatge correspon a fill/es, néts/es (84\%) i a nebodes (16\%). Per sexe, hem entrevistat un $79 \%$ de dones. Per últim, un $79 \%$ tenien en el moment de les entrevistes 70 anys o més.

La durada mitjana de les entrevistes va ser d'una hora i mitja. Van ser recollides en la majoria del casos al domicili particular dels informants (16). La resta, 3 a una cafeteria i 1 al lloc de treball de l'entrevistat. La llengua del 100\% de les entrevistes fou el valencià, llengua materna de tots els entrevistats, i que s'ha mantingut en la transcripció literal. S'han respectat les variants dialectals particulars de cada comarca, així com els castellanismes i les paraules i expressions en anglès, en el cas que esta fora també la llengua utilitzada per l'informant (assenyalant-ho amb cursiva).

\begin{tabular}{|c|c|c|c|c|c|c|c|}
\hline PROVÍNCIA & COMARCA & POBLACIÓ & SEXE & EDAT & PARENTESC & $\begin{array}{l}\text { DATA } \\
\text { EMIGRACIÓ }\end{array}$ & $\begin{array}{l}\text { DATA } \\
\text { RETORN }\end{array}$ \\
\hline \multirow{3}{*}{ Alacant } & Comtat & Benilloba & $\begin{array}{l}\text { Dona } \\
\text { Dona } \\
\text { Dona }\end{array}$ & $\begin{array}{l}85 \\
82 \\
74\end{array}$ & $\begin{array}{l}\text { Filla } \\
\text { Filla } \\
\text { Filla }\end{array}$ & $\begin{array}{l}1919 \\
1920 \\
1920\end{array}$ & $\begin{array}{l}1921 \\
1930 \\
1922\end{array}$ \\
\hline & \multirow[b]{2}{*}{$\begin{array}{l}\text { Marina } \\
\text { Alta }\end{array}$} & Orba & $\begin{array}{l}\text { Home } \\
\text { Dona }\end{array}$ & $\begin{array}{l}85 \\
53\end{array}$ & $\begin{array}{l}\text { Fill } \\
\text { Filla i néta }\end{array}$ & $\begin{array}{l}\text { 1916, } 1920 \\
\text { ant.i } 1933\end{array}$ & Anys 80 \\
\hline & & Pego & $\begin{array}{l}\text { Home } \\
\text { Dona } \\
\text { Dona } \\
\text { Dona }\end{array}$ & $\begin{array}{l}74 \\
55 \\
55 \\
79\end{array}$ & $\begin{array}{l}\text { Fill } \\
\text { Filla i néta } \\
\text { Neboda } \\
\text { Neboda }\end{array}$ & $\begin{array}{l}1920 \\
1920 \\
1917 \\
1917\end{array}$ & $\begin{array}{l}1923 \\
1930 \\
\text { No torna } \\
\text { No torna }\end{array}$ \\
\hline & \multirow{3}{*}{ Safor } & Bellreguard & Dona & 85 & Filla & 1920 & 1921 \\
\hline & & Palmera & Dona & 75 & Neboda & 1920 & No torna \\
\hline & & & Home & 70 & Fill & 1920 & 1922 \\
\hline
\end{tabular}




\section{perifèria}

Número 20 (2), diciembre 2015

revistes.uab.cat/periferia

\begin{tabular}{|c|c|c|c|c|c|c|c|}
\hline València & $\begin{array}{l}\text { Ribera } \\
\text { Alta }\end{array}$ & Carlet & $\begin{array}{l}\text { Dona } \\
\text { Dona } \\
\text { Dona } \\
\text { Home }\end{array}$ & $\begin{array}{l}92 \\
91 \\
80 \\
74\end{array}$ & $\begin{array}{l}\text { Filla } \\
\text { Filla } \\
\text { Filla } \\
\text { Fill }\end{array}$ & $\begin{array}{l}1920 \\
1920 \\
1920 \\
1920\end{array}$ & $\begin{array}{l}1921 \\
1922 \\
1922 \\
1933\end{array}$ \\
\hline & & Guadassuar & $\begin{array}{l}\text { Dona } \\
\text { Dona } \\
\text { Dona }\end{array}$ & $\begin{array}{l}50 \\
74 \\
74\end{array}$ & $\begin{array}{l}\text { Filla i néta } \\
\text { Filla } \\
\text { Filla }\end{array}$ & $\begin{array}{l}1920 \\
1920 \\
1920\end{array}$ & $\begin{array}{l}\text { Anys } 60 \\
1921 \\
1932\end{array}$ \\
\hline
\end{tabular}

Taula 1. Informants segons criteris.

Una vegada realitzada la transcripció de les entrevistes es va realitzar el seu buidat per establir una sèrie de categories d'anàlisi.L'establiment i concreció d'unes categories d'anàlisi conceptuals extretes de les nostres entrevistes ens permetran teoritzar i validar les hipòtesis de partida de la nostra investigació. Aporten una informació en molts casos de tipus descriptiu, però també mostren tot un món simbòlic i interpretatiu d'un fenomen com l'emigració als Estats Units d'Amèrica que ens ofereix, més enllà de com va ser viscut, com va ser i encara ho és, pensat, pels familiars d'aquells que van ser emigrants.

Dintre de les categoriesaquella que fa referència al contextos sociofamiliars $i$ a les causes per a l'emigració és de les primeres en sorgir dels relats.El tipus de família que es trobava tradicionalment a les terres valencianes (per altra part la que es trobava majoritàriament al centre i sud de la Península Ibèrica) era la família nuclear associada amb una residència neolocal. El sistema de transmissió del patrimoni (en el cas d'haver-ne) era de tipus distributiu, dividint-se I'herència a parts iguals entre fills i filles d'una família. Açò, a efectes pràctics, donava lloc a una fragmentació del patrimoni, que en el cas de ser terra originava un minifundisme poc rendible $i$ insuficient (Comas d'Argemir, 1992). En una època on la transició demogràfica a una societat moderna encara no s'havia completat, la natalitat continuava sent molt alta mentre que la mortalitat anava a poc a poc minvant. Un nombre elevat de fills i filles, unit a la falta de patrimoni $\mathrm{i}$ unes condicions socioeconòmiques adverses empentaven a l'emigració. A més a més si a 


\section{perifèria}

Número 20 (2), diciembre 2015

revistes.uab.cat/periferia

això s'afegien causes com algun desajust familiar (viduïtat, orfandat, malalties) la situació podia tornar-se insostenible per al nucli familiar.

"Mon pare, son pare va morir quan ell era jovenet i lo mateix va passar a ma mare, que la seua mare va morir molt més prompte... (Home, 84 anys, Orba)."

"És que passava que ells no tenien pare, ma uela es va quedar sense home i ell als onze anys va tindre que eixir d'escola i ficar-se a treballar, tres filles i un fill. (Dona, 80 anys, Carlet)."

"Mon pare eren dos germans i una germana i sa mare era viuda. (Dona, 85 anys, Benilloba)."

"Mon pare eren set germans. Tres van emigrar a Nord-Amèrica, per cert, van anar a Washington, i a New York. (Home, 74 anys, Pego)."

"No estaven mal econòmicament, lo que passa es que ma uelo es va posar mal i ma uela no va saber administrar el negoci i es gastaria els diners en metges... I es veu que mon pare, que ja s'havia casat i ma mare estava en estado de la meua germana major, va dir, me'n vaig a guanyar diners. (...) Ma uela va acabar, com aquell que diu, en tot. Es gastaren els diners per la malaltia de ma uelo. I endespués, a vorà, mon pare quan es va casar, venien en casa, però també anaven als mercats en carro, al mercat de Benissa, al mercat de ....a vendre arròs, grans de tota classe. I mon pare pos feia això. I m'auelapos es va quedar empenyài la botiga va anar acabant-se. (Dona, 85 anys, Bellreguard)."

"Ma uelo era el major d'un matrimoni mixto ${ }^{13}$. Ma uelo, és que a son pare li agradava beure.(...) Perquè son pare si que tenia! tenia una casa ahi enfront

\footnotetext{
${ }^{13}$ Es refereix a que el seu besavi era vidu amb 3 o 4 fills i es va casar amb una dona que també era vídua amb fills. Entre els dos en tingueren més. El seu avi era el major i va veure que no hi havia prou per a tots
} 


\section{perifèria}

Número 20 (2), diciembre 2015

revistes.uab.cat/periferia

de l'ajuntament que era de son pare, i més...però, si tenen una barca de fills d'una dona i d'una altra dona, i beuen i...(Dona, 74 anys, Guadassuar)."

"Tenien sis fills, eh, van tindre sis fills. Este home es va morir no arribava als cinquanta anys, no?. I bueno, pos això, es van quedar sense pare i entonces a partir d'ahi ja... (Dona, 55 anys, Pego)."

"Mon pare es va quedar sense pare molt xicotet. Eren sis o set germans, ell era el més menut i quan son pare es va morir no sé si tindria dos o tres anys. I en sa casa tenien terra però resulta que sa mare era juaora, vull dir, que li agradava el joc $\mathrm{i}$ es coneix que poc a poc ho va anar perdent tot i empenyantho i hipotecant-se. (Home, 74 anys, Carlet)."

Aquestes circumstàncies afegides a la situació econòmica i política general es presenten en la majoria dels casos com les causes i motius per l'emigració. Malgrat que no és el lloc per tractar el context històric a nivell nacional, provincial o comarcalcal assenyalar que el moment històric en que es produeix l'emigració cap als EEUU va ser una situació en general de crisi socioeconòmica, agreujada la segona dècada del segle XX per les repercussions de la I Guerra Mundial sobre l'economia valenciana. L'entorn del que eixiren els emigrants va ser una societat agrícola colpejada per una forta crisi. En les entrevistes aquesta situació s'expressa de formes diverses. El gruix de l'emigració el formaren aquells que no posseïen terra i anaven a jornal.

"En casa de mon pare no tenien terra. (Dona, 91 anys, Carlet)."

"En casa no tenien terra, anaven a jornal. Ell se'n va anar a Amèrica en un familiar quan tenia dèsset anys. (Dona, 72 anys, Guadassuar)."

"Pues perquè eren tots pobrets. Ací en el poble només hi havien que quatre ricots, que la terra casi tota era de quatre ricots ( $i$ els atres anaven a jornal). I a jornal antes no és com ara. Però, però la gent se n'anava a això, pa prosperar. I tindre... Ma uelo no volia viure a jornal, ma uelo volia viure de lo 


\section{perifèria}

Número 20 (2), diciembre 2015

revistes.uab.cat/periferia

d'ell. I quan va vore la primera volta que no tenia prou, per això se'n va tornar a anar, pa viure com volia. (Dona, 74 anys, Guadassuar)."

L'emigració va ser també una de les estratègies d'adaptació al mercat i en alguns casos de resistència a l'estat (en el cas dels que fugien de fer el servici militar a I'Africa, per exemple) de la qual feren ús les famílies normals i corrents per sobreviure i intentar millorar les seues condicions de vida i laborals. El desig d'anar-

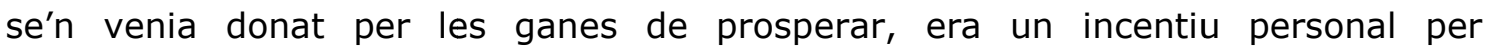
aconseguir unes millors condicions laborals i millor nivell de vida.

En altres casos, homes ja amb edat de casar-se, emprenien el viatge amb l'objectiu molt clar, fer diners per poder-se casar.

"(Ell se n'anà a Amèrica) Perquè ací no hi havia faena i anava a casar-se i va anar allàpa guanyar diners pa casar-se. (Dona, 91 anys, Carlet)."

"És que mon pare va anar a arreplegar diners pa poder-se casar. Festejava, festejava i no hi havien diners pa casar-se. (Dona, 80 anys, Carlet)."

"I ell va dir: si jo ara em case els pocs ahorros que té ma mare me'ls enduc jo. I diu pos me'n vaig a Amèrica i lo que traga pos pa casar-me. (Dona, 85 anys, Benilloba)."

No obstant totes aquestes explicacions econòmiques, també es troba qui en dóna de ben diferents. Homes amb una posició econòmica més benestant, que emprenien el viatge com una aventura o amb ganes de veure món i eixir del poble.

"Mon pare era carnisser i se'n va anar en el tio X, que era llumener. Els dos tenien un bon passar, no els feia falta res. Acabaven de posar la llum en el poble i este home havia guanyat molts, molts dines. I dirien, oi, pos anem a vore que trobem per allà. (Dona, 92 anys, Carlet)."

"[...] Perquè per necessitat tampoc era perquè en casa tenien un mig de vida, lo únic que passa és que, seria per aventura i...a vore, gent jove. (Home, 70 anys, Carlet)." 


\section{perifèria}

Número 20 (2), diciembre 2015

revistes.uab.cat/periferia

Encara que l'emigració als Estats Units d'Amèrica va ser majoritàriament masculina, entre algunes dones el desig d'emigrar també estava present i no sols per anar darrere del pare o el marit. Era l'expressió d'un anhel per eixird'una societat agrícola on el progrés ola mobilitat social es mostrava quasi impossible. Així ho manifesta una neboda d'una d'aquelles dones.

"Jo li sentia a ma uela que la germana (Dolores) volia anar-se'n i això...i sa mare, o siga la uela Dolores feia: i tu a que has d'anar allí! ? i diu : jo me'n vaig perquè vull portar sombrero! (rialles) (Dona, 55 anys, Pego)."

Juntament a les motivacions econòmiques o de caire sociofamiliars, l'establiment de xarxes les quals, més enllà de les circumstàncies desfavorables al lloc d'origen - a I'atracció que exercia un país com els EEUU, reforçaven i estimulaven l'emigració. Tot pareix apuntar en la nostra investigació que l'emigració dels valencians als EEUU d'Amèrica no va ser un fenomen aïllat d'unes quantes persones amb ganes d'aventura. Els EEUU eren ja en aquella època un gran focus d'atracció per a milions de persones del tot el món i, com ja hem assenyalat, encara que per els valencians no fóra una destinació molt comuna, s'establiren una sèrie de cadenes o xarxes que iniciades a la comarca alacantina de la Marina Alta, es van estendre per les comarques veïnes fins arribar fins i tot a Castelló.

"I hi havia un puesto molt important que es deia "La valenciana". "La valenciana" eren dos socios. Un era Manuel Ivars. El nom Ivars és de Benissa. I l'altre era Francisco Sendra, que era tio de mon pare. Tenia el seu negoci allí, "La valenciana". I tots els fins de setmana pues, vivíem allí propet i anàvem a vore com anaven els negocis. Lo que em va xocar es que quan venia l'home del correu, hi havia al centro de la tenda...tot era roba per a homes...per vendre. I venien tabaco, sabates, pantalons...i dalt de lo que es diu "La Valenciana", dalt tenien dos pisos per a alquilar per a homes que volien, que tenien treball propet i dormien allí. Pues...me xocava vore quan venia el correu agarrava i en un estutx de tabaco, de puros, allí ficava les cartes. Jo dic, com pot ser això? les cartes és una cosa de importància individual, privat, i les posava allí. Pues tots els homes que treballaven per allí 


\section{perifèria}

Número 20 (2), diciembre 2015

revistes.uab.cat/periferia

anaven a vore de ves en cuant, a vore si hi havia una carta de la mare o pare d'Espanya. [...](Home, 84 anys, Orba)."

"Però allí ma mare ja tenia faena a altres puestos, treballava a diferents fàbriques: de sombreros, de teles. Es que a Manhattan hi havia, hi ha un barrio que tot és de roba, especialment de dones i hui en dia tot això s'exporta de Xina i altres puestos. I ma mare, pues, va tindre molta sort. Quan vam aplegar de New Jersey a Manhattan ha conegut molts amics que eren d'Oliva, Pedreguer, Ondara, Benigembla i li van dir: tu vols treballar en mosatros? I diu: si, si. (Home, 84 anys, Orba)."

Els nostres informants ens parlen de com allà, els seus pares, avis o tios es trobaven amb altres dels seus pobles o es dirigien allà on ja es trobaven vivint $i$ treballant valencians. Açò es va veure encara més reforçat per la costum, tan habitual al camp valencià, de treballar en colles o quadrilles (Mira 1982; Cucó 1992). En molts casos eren eixes colles d'homes senceres les que emigraven seguint l'estela d'altres colles que possiblement havien compartit les feines del camp. ${ }^{14}$

"[...] en deneu anys, dirien pues anem. Igual sentirien dir d'una quadrilla d'homes que se n'anaven...(Home, 70 anys, Carlet)."

"[...] ahi ho posa, ahi em pense que hi ha més. Si, se'n van anar varios junts.

$\mathrm{Si}$, ací fica varios noms de Benilloba: Francisco, Silvestre,..(Dona, 85 anys, Benilloba."

"[...]Ma tia es va casar en un senyor de ...mon tio Pedro, que és de Benigembla. I entonces...Benigembla es un poble que esta ahidalt de... en la part d'Orba, per ahi. I eixe poble era un poble menudet. Si eren dos mil habitants, que no tinc clar que en son tants, més de la meitat se'n van anar tots capallà. I entonces mon tio Pedro se'n va anar davant, que es van casar per cert pa anar-se'n a Amèrica perquè els pares d'ell ja havien anat. Fixat,

\footnotetext{
${ }^{14}$ Una revisió realitzada als arxius de l'illa d'Ellis mostra com en els vaixells on viatjaven valencians aquestos solien estar agrupats per pobles (www.libertyellisfoundation.org).
} 


\section{perifèria}

Número 20 (2), diciembre 2015

revistes.uab.cat/periferia

això seria pues igual en el 1916 aproximadament. I se n'anaren davant. I va estar allà dos anys, despues va anar ma tia Joaquina [...]. I estantallà tot era insistir-li a mon pare i a una altra germana que també volia anar. Però clar, resulta que era la penúltima i entonces era molt joveneta per anar. I total que ella se'n va anar (Joaquina) i quan feia dos anys que estava allí, seria aproximadament el 1918, va vindre i mon pare se'n va anar en ella en el 1920"(Home, 74 anys, Pego)."

"Però va tindre la sort que va estar en una casa d'espanyols. Ell feia, diu, si jo menjar d'allí no n'he menjat, perquè menjava com si estigués ací! perquè era un matrimoni espanyol. Era un germà del tio $\mathrm{X}$, d'ací del poble també. (Dona, 85 anys, Benilloba)."

"[...] Si, si, no veus que s'ajuntaven tots als mateixos llocs? Al ser catòlics, anaven a l'església catòlica. Després anaven, si feien ball, s'ajuntaven tots espanyols i si podia ser valencians millor. Perquè l'idioma facilitava molt les coses. (Dona, 55 anys, Pego)."

"Dolores que se'n va anar despues (ja tenia un germà allà) perquè se n'anava en I'home i l'home d'ella no tenia ganes d'anar. I ella diu, pos si tu no vens me'n vaig jo i diu "pos Pasqual, on va la corda va el poal" i se'n va anar en ella. (Dona, 79 anys, Pego)."

"I tenien un cosí germà allà ja.... (Dona, 55 anys, Pego)."

\section{Conclusions}

Segons I'antropòloga Marie-José Devillard, "el uso de los relatos de vida se justifica porqueconstituyen un instrumento pertinente y eficaz para poner de relieve $y$ descubrirhechos y procesos (viaje, trabajo, matrimonio...) que han marcadogenéticamente la trayectoria del agente social considerado $[\ldots]$, y para averiguar (mediante la comparación) las regularidades que permitan dar cuenta de los modos de vida y acción" (2004:168). No obstant això, som conscients, juntament a esta autora, de les limitacions de les investigacions del passat. No esperem ni pretenem que les entrevistes biogràfiques en profunditat restablisquen 


\section{perifèria}

Número 20 (2), diciembre 2015

revistes.uab.cat/periferia

totes les dimensions de la gènesi social dels fets passats. Encara que l'aproximació biogràfica a l'estudi de les migracions del passat no és hui en dia cap novetat si ho és la seua aplicació per a la recuperació d'uns processos pràcticament oblidats, que a altres zones de Espanya han sigut ben estudiades i han estat sempre presents (gallecs i asturians) però que al territori valencià havien passat pràcticament desapercebuts.

La intenció de l'article era mostrar com recorden, com s'expressen i com interpreten el fet de l'emigració cap als EEUU a l'inici del segle XX alguns dels descendents dels emigrants originals. Només hem exposat una xicoteta mostra de la informació recollida però aquesta ja fa palesa la potencialitat que ofereix una tècnica qualitativa com les narracions biogràfiques i la riquesa d'esta informació. Combinada amb altres tècniques com la redacció d'un diari de camp, I'anàlisi de materials i documents personals com ara correspondència, fotografies, etc., el buidat d'arxius consulars, etc. aporten a l'investigador social una informació del tot fonamental. Primerament, a un nivell més descriptiu, per a reconstruir uns fets històrics que no han quedat apenes reflectits en fonts oficials o històriques tradicionals. En segon $\mathrm{lloc}$, ens permet comprendre com els esdeveniments del passat han conformat la identitat individual i col-lectiva d'alguns dels pobles i comarques de la geografia valenciana, a través de canvis culturals, socials o econòmics. Ens obri les portes a l'aplicació de nous corrents teòrics en l'estudi de les migracions, com ara el transnacionalisme15, a l'estudi d'uns fets del passat. Ens permet entendre com els emigrants que eixiren dels seus pobles submergits encara en una societat endarrerida, agrícola, tradicionals'inseriren en uns corrents mundials cap una societat en procés de transformació modernitzadora, urbana i industrial i foren capaços, a pesar de les limitacions de l'època, de transmetre coneixement, capital, cultura, valors a través d'objectes, cartes, fotografies, als seus llocs d'origen i a les seues famílies. La importància dels vincles transnacionals apareix per tant dibuixada mitjançant tot un entramat on les xarxes establides $\mathrm{i}$ formades pels emigrants valencians es mostren com a proveïdores de suport

\footnotetext{
${ }^{15}$ Tal i com han sigut definit per GlickSchiller; Basch,i Szanton Blanc, (1995) i GlickSchiller (2013).
} 


\section{perifèria}

Número 20 (2), diciembre 2015

revistes.uab.cat/periferia

econòmic, laboral, social i fins i tot emocional, per aquells homes i dones que, lluny del seu entorn, fan d'estes xarxes l'element fonamental per a la seua supervivència. Aquestos vincles sobrepassen els límits territorials i tenen repercussions a la vida diària de cadascú dels membres que formen part de les xarxes, tant al lloc d'origen de l'emigrant com al nou país on intenta establir-se, afectant fins i tot membres de diferents generacions. Així, els conceptes de transmigrant o camps transnacionals, definits per a l'estudi de les migracions contemporànies poden ser aplicats perfectament als emigrants del passat.

"Jo m'enrecorde que quan venien sempre portaven regalets, roba sobre tot i collars. Jo encara ho tinc perquè jo faig teatre i m'ho guarde tot això. Però jo m'enrecorde que era menuda i mos van portar per a tots els xiquets una piruleta que era un boli. I això ací no s'havia vist mai. Jo me n'anava a escola en això i triomfava! Allò triomfava! Un boli que pareixia una piruleta! I tenia un convoi! Es que clar,m'ho havien portat d'Amèrica. Allò era una cosa gran!. (Dona, 55 anys, Pego)."

\section{Bibliografia}

Bonmatí, José Fermín (1988). La emigración alicantina a Argelia. Alicante: Universidad de Alicante.

Comas d'Argemir, Dolors [et al.] (1990). Vides de dona: treball, família i sociabilitat entre les dones de classes populars (1900-1960). Barcelona: Alta Fulla.

Comas d'Argemir, Dolors (1992). "Matrimonio, patrimonio y descendencia. Algunas hipótesis referidas a la Península Ibérica", en Chacón, Francisco i Hernández, Juan (eds.)Poder, familia y consanguinidad en la España del Antiguo Régimen. Barcelona: Anthropos, pp. 157-175.

Cucó, Josepa(1992). "Familia, ideología y amistad en Cataluña y el País Valenciano". Anales de la Fundación Joaquín Costa, 9: 109-122.

Devillard, Marie-Jose (2004). "Antropología social, enfoques (auto)biográficos yvilgilancia epistemológica". Revista de Antropología Social, 13: 161-184. 


\section{perifèria}

Número 20 (2), diciembre 2015

revistes.uab.cat/periferia

Dornier-Agbodjan, Sarah (2004). "Fotografías de familia para hablar de memoria". Historia, Antropología y Fuentes Orales, 2, 32: 123-132.

Feixa, Carles (2006). "La imaginación autobiográfica". Perifèria, 5:

García-Hernandorena, Pepa (2013). "Una aventura americana. Carletins als Estats Units d'Amèrica".Carletins, Fundació Caixa Carlet, 1: 50-55.

Glick-Schiller, Nina; Basch, Linda i Szanton-Blanc, Cristina (1995). "From Immigrant to Transmigrant: TheorizingTransnationalMigration".AnthopologicalQuaterly, 68, 1: 48-63. http://www.jstor.org/stable/3317464

Glick Schiller, Nina (2013). "Thetransnationalmigrationparadigm: global perspectives on migrationresearch", en Halm, Dirk i Sezgin, Zeynep (eds.)Migration and Organized Civil Society: RethinkingNational Policy. Nova York: Routledge.

INFO TV (2014. Del Montgó a Manhattan. Valencians a Nova York. València. (DVD) Marinas, José Miguel i Santamarina, Cristina (eds.)(1993). La historia oral: métodos y experiencias. Madrid: Debate.

Menages, Àngela-Rosa i Monjo, Josep-Lluís (2007). Els valencians d'Algèria (18301962). Picanya: Edicions del Bullent, S.L.

Mira, Joan Francesc (1982). "Propiedad de la tierra y estratificación en una sociedad agraria tradicional". en VVAA (1982) Estructura Social al País Valencià. València: Diputació de València, pp.359-372.

Mira, Joan Francesc (1993). "La migración valenciana al área de Nueva York".Jornadas sobre la emigración: los valencianos en América. València: edició a càrrec de Pérez de Guzmán, Torcuato, Generalitat Valenciana.

Moncusí, Albert (2007). "Segundas Generaciones". ¿La inmigración como condición hereditaria?". AIBR Revista de Antropología Iberoamericana, vol.2, 3:459-487.

Morell, Teresa (2012). Valencians a Nova York. El cas de la Marina Alta (19121920). La Pobla Llarga: Edicions 96 i Institut d’Estudis Comarcals de la Marina Alta. Morrió, Enric (2014). "Benillobers als Estats Units d'Amèrica".Alberri.24: 213-261. 


\section{revista de recerca i formació en antropologia}

\section{perifèria}

Número 20 (2), diciembre 2015

revistes.uab.cat/periferia

Ortuño, Vicent (2013). Fent les Amèriques (Ondara, 1912-1920). La Pobla Llarga: Edicions 96.

Prat, Joan (2007a). Los sentidos de la vida. La construcción del sujeto, modelos delyo e identidad. Barcelona: Bellaterra.

Prat, Joan (2007b). "En busca del paraíso: historias de vida y migración". Revista de Dialectología y Tradiciones Populares, vol. LXII: 21-61.

Pujadas, Joan Josep (2000). "El método biográfico y los géneros de la memoria" Revista de Antropología Social, 9: 127-158.

Pujadas, Joan Josep [1992] (2000). El método biográfico: el uso de las historias de vida en ciencias sociales. Madrid: CIS, colección "Cuadernos Metodológicos", 5.

Rueda, Germán (1993). La emigración contemporánea de españoles a Estados Unidos. Madrid: MAPFRE.

Sánchez, Blanca (1995). Las causas de la emigración española, 1880-1930. Madrid: Alianza Editorial.

Thomas, William I. i Znaniecki, Florian (2004). El campesino polaco en Europa y en América. Madrid: CIS.

Varela-Lago, Ana Ma (2008). Conquerors, Immigrants, Exiles: TheSpanishDiaspora in theUnitedStates (1848-1948). Tesi doctoral Universitat de Califòrnia, San Diego. 